\title{
Case report: breast cancer associated with contralateral tuberculosis of axillary lymph nodes
}

\author{
Muna M Baslaim*, Shefaa A Al-Amoudi, Masoud A Al-Ghamdi, Abdullah S Ashour and Taha S Al-Numani
}

\begin{abstract}
Background: Breast cancer coexisting with tuberculous axillary lymph nodes is rare.

Case report: We report a 69 years old Yemeni patient with a left breast invasive ductal carcinoma associated with contralateral tuberculous axillary lymph nodes containing microcalcifications mimicking malignancy. The patient had to be investigated for the possibility of bilateral breast cancer since she had no history of previous exposure to tuberculosis.

Conclusion: Tuberculosis involving lymph nodes can create a diagnostic dilemma in the presence of a malignant process. The presence of calcifications in lymph nodes should raise the possibility of tuberculosis even in the absence of contact history with tuberculosis.
\end{abstract}

Keywords: Breast cancer, Tuberculosis, Axillary lymph nodes

\section{Background}

The synchronous occurrence of carcinoma and tuberculosis is unusual. The earliest known report of such a case is that of Pilliet and Piatot in 1897 [1]. After that and in 1899, Warthin reported the first case of coexisting tuberculosis and cancer in axillary lymph nodes [2]. Tuberculosis can produce masses and nodes that can imitate or complicate staging of the neoplastic disease [3].

We report a case of breast cancer with contralateral tuberculous axillary lymph nodes that created a diagnostic dilemma and raised the possibility of a bilateral breast cancer.

\section{Case presentation}

A 69-year-old Yemeni woman presented to the breast clinic with a left breast painless mass increasing gradually in size over a few months. Lately she had noticed that the left nipple started to ulcerate and retract. Eight years ago, she had had colonic carcinoma, which was managed with left hemi-colectomy followed by chemotherapy and radiotherapy. She was from a high socioeconomic class, living in Saudi Arabia for more than 20 years and did not recall contact with patients with tuberculosis. Examination of the left breast showed a retracted ulcerated nipple; the

\footnotetext{
* Correspondence: munabaslaim@hotmail.com

King Fahd General Hospital, P. O. Box: 51652, Jeddah 21553, Saudi Arabia
}

skin was thickened making with the underlying mass an irregular large palpable area measuring $15 \times 12 \mathrm{~cm}$ in maximum dimensions and there were no palpable axillary lymph nodes. Right breast examination was unremarkable but there was a rounded firm mobile 2-cm lymph node high up in the right axilla.

Bilateral mammogram showed a left breast stellate retro-areolar lesion with nipple retraction (Figure 1A). The right breast was normal, however, there was a suspicious large rounded dense right axillary lymph node containing multiple calcifications (Figure 1B). Bilateral breast magnetic resonance imaging (MRI) showed multiple enhanced large suspicious right axillary lymph nodes; the largest one measured $2.3 \mathrm{~cm}$ with no evidence of a primary right breast lesion. Computed tomography (CT) showed multiple enlarged right axillary lymph nodes with calcifications. CT of the chest, abdomen and pelvis, as well as a bone scan showed no evidence of other pathology or distant metastases.

Tru-cut needle biopsy of the left breast mass showed invasive ductal carcinoma (IDC), grade II, and fine needle aspiration (FNA) of the right axillary lymph node was insufficient for diagnosis. Repeat FNA was not attempted. The patient was reluctant to receive neoadjuvant chemotherapy since she had a prior history of chemotherapy as a treatment for colonic cancer. She underwent left modified radical mastectomy and right 

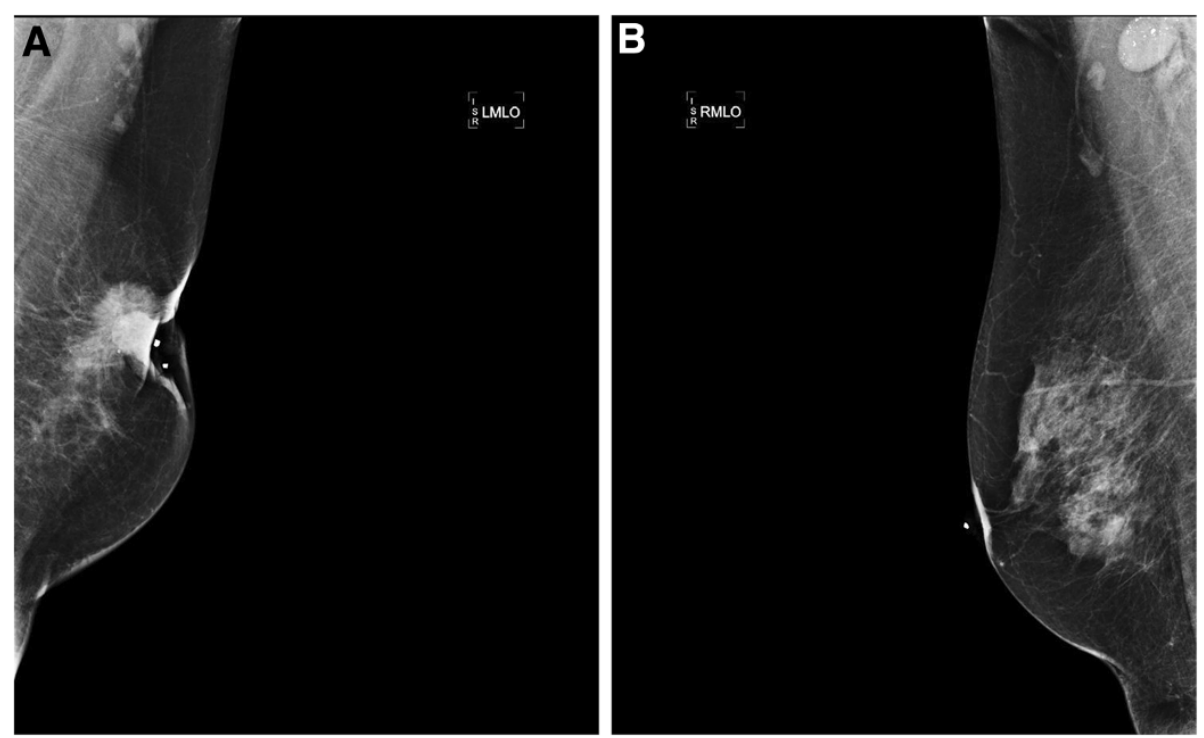

Figure 1 Bilateral mammography A. Left-sided mammogram showing a stellate lesion in the retro-areolar area with skin involvement and nipple retraction. B. Right-sided mammogram showing a large rounded axillary lymph node with calcifications.
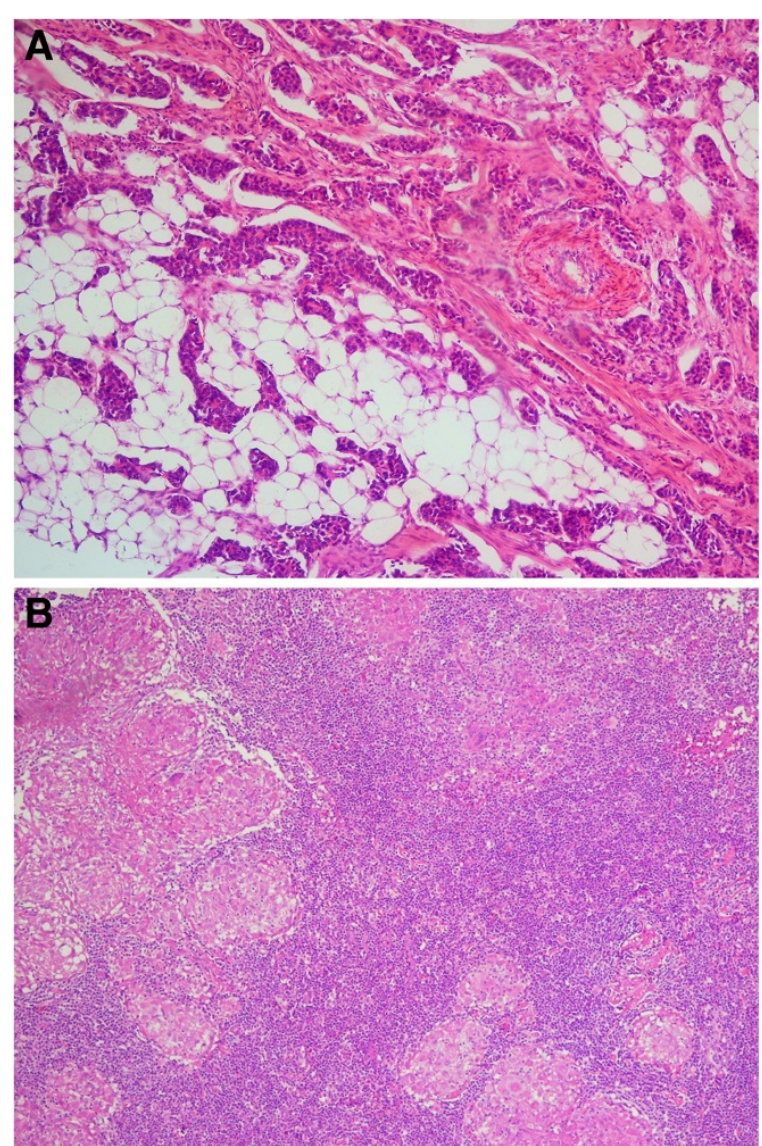

Figure 2 Histopathology of the breast carcinoma and lymph nodes A. Invasive ductal carcinoma of the left breast infiltrating surrounding fat and stroma (haematoxylin and eosin stain, 10x magnification). B. Lymph node containing multiple well-defined granulomas with central caseation containing giant cell (haematoxylin and eosin stain, 10x magnification). 
axillary lymph node excision. Final histopathology showed left breast IDC, grade II (Figure 2A), with metastases in 10 lymph nodes out of 16 dissected. The lesion in the right axilla was a group of matted lymph nodes forming one mass; there were granulomatous lesions with caseation consistent with tuberculosis (Figure 2B).

The coexistence of tuberculosis and malignancy has been reported in the literature mainly with Hodgkin's lymphoma, sarcoma, leukemia, or lung cancer. It is least prevalent in patients with carcinoma of the colon, bladder, uterus, breast, prostate, and kidney [3].

Most of the reported cases of breast cancer with concomitant tuberculous axillary lymph nodes were of ipsilateral involvement [4-9]. Our patient created a diagnostic dilemma clinically and radiologically, since a malignant right axillary lymph node was suspected with no evidence of a primary lesion in the breast; hence a bilateral breast cancer was suspected. Moreover, breast MRI did not exclude malignant right axillary lymph nodes. Yang et al. reported a case of tuberculous axillary lymph node that was misinterpreted by ${ }^{18} \mathrm{~F}$ - fluorodeoxyglucose positron emission tomography (FDG-PET) as a malignant metastatic disease from a possibly occult breast cancer [10].

Extensive surgery such as axillary dissection can be avoided by clinically suspecting granulomatous disease with assessment of intraoperative frozen sections.

\section{Conclusion}

In cancer patients, a tuberculous lymph node should be suspected whenever an enlarged lymph node shows calcifications on radiography, even without history of exposure to tuberculosis.

\section{Consent}

Written informed consent was obtained from the patient for publication of this report and any accompanying images.

\footnotetext{
Abbreviations

CT: Computed tomography; FDG-PET: ${ }^{18}$ F-fluorodeoxyglucose positron emission tomography; FNA: Fine needle aspiration; IDC: Invasive ductal carcinoma; MRI: Magnetic resonance imaging.
}

\section{Competing interests}

The authors declare that they have no competing interests.

\section{Authors' contributions}

$M B, S A, M A, T A$, and $A A$ were involved in the conception of the report and acquisition of data. SA, MA, and TA were involved in the acquisition of images. $M B$, and $A A$ drafted the manuscript. MB, SA, MA, TA, and AA corrected and revised the manuscript. MB, SA, MA, TA, and AA approved the final version for publication. All authors read and approved the final manuscript.

Received: 21 October 2012 Accepted: 16 February 2013

Published: 25 February 2013

\section{References}

1. Miller RE, Salomon PF, West JP: The coexistence of carcinoma and tuberculosis of the breast and axillary lymph nodes. Am J Surg 1971, 121:338-340.

2. Warthin AS: The coexistence of tuberculosis and carcinoma of the mammary gland. Am J Med Sci 1899, 118:25.

3. Kaplan MH, Armstrong D, Rosen P: Tuberculosis complicating neoplastic disease: a review of 201 cases. Cancer 1974, 33:850-858.

4. Robinson AJ, Horne CA, Weaver A: Coexistence of axillary tuberculous lymphadenitis with lymph node metastases from a breast carcinoma. Clin Oncol (R Coll Radiol) 2001, 13:144.

5. Fujii T, Kimura M, Yanagita Y, Koida T, Kuwano H: Tuberculosis of axillary lymph nodes with primary breast cancer. Breast Cancer 2003, 10:175-178.

6. Pandey M, Abraham EK, Chandramohan K, Rajan B: Tuberculosis and metastatic carcinoma coexistence in axillary lymph node: a case report. World J Surg Oncol 2003, 1:3.

7. Tulasi NR, Raju PC, Damodaran V, Radhika TS: A spectrum of coexistent tuberculosis and carcinoma in the breast and axillary lymph nodes: report of five cases. Breast 2006, 15:437-439.

8. Khurram M, Tariq M, Shahid P: Breast cancer with associated granulomatous axillary lymphadenitis: a diagnostic and clinical dilemma in regions with high prevalence of tuberculosis. Pathol Res Pract 2007, 203:699-704.

9. Salemis NS, Razou A: Coexistence of breast cancer metastases and tuberculosis in axillary lymph nodes-a rare association and review of the literature. Southeast Asian J Trop Med Public Health 2010, 41:608-613.

10. Yang $\mathrm{CM}$, Hsu CH, Hsieh CM, Chen MY: ${ }^{18}$ F- FDG PET in a clinical unsuspected axillary tuberculous lymphadenitis mimicking malignancy. Ann Nucl Med Sci 2003, 16:107-110.

\section{doi:10.1186/1477-7819-11-43}

Cite this article as: Baslaim et al:: Case report: breast cancer associated with contralateral tuberculosis of axillary lymph nodes. World Journal of Surgical Oncology 2013 11:43

\section{Submit your next manuscript to BioMed Central and take full advantage of:}

- Convenient online submission

- Thorough peer review

- No space constraints or color figure charges

- Immediate publication on acceptance

- Inclusion in PubMed, CAS, Scopus and Google Scholar

- Research which is freely available for redistribution 